\title{
Optimizing the Glass Fiber Cutting Process Using the Taguchi Methods and Grey Relational Analysis
}

\author{
Chao-Lieh Yang \\ Department of Industrial Engineering and Management Information, Huafan University, New Taipei City, Chinese Taipei. \\ Email:ygcl@ms38.hinet.net
}

Received March 10 ${ }^{\text {th }}, 2011$; revised March 21 ${ }^{\text {st }}, 2011$; accepted April $6^{\text {th }}, 2011$.

\begin{abstract}
This paper mainly describes a new approach to optimizing of the cutting glass fiber with multiple performance characteristics, based on reliability analysis, Taguchi and Grey methods. During the cutting process, the speed, the volume and the cutting load are optimized cutting parameters when the performance characteristics, which include Weibull modulus and blade wear, are taken into consideration. In this paper, optimization with multiple performance characteristics is found to be the highest cutting speed and the smallest cutting volume, and the medium cutting load. An analysis of the variance of the blade wear indicates that the cutting speed (47.21\%), the cutting volume (14.62\%) and the cutting load (12.20\%) are the most significant parameters in the cutting process of glass fibers. In summary, the most optimal cutting parameter should be $A 3 B 1 C 2$. The results of experiments have shown that the multiple performance characteristics of cutting glass fiber are improved effectively through this approach.
\end{abstract}

Keywords: Blade Wear, Cutting, Glass Fiber, Grey Relational Analysis, Optimizing, Taguchi Methods

\section{Introduction}

Composite materials are playing an important role in a wide range of fields and replacing many traditional engineering materials. Glass fiber reinforced composite materials are a class of materials used in various products including aerospace, automobile, sporting goods, marine bodies, plastic pipes, storage containers, etc. An et al. [1] glass fiber reinforced plastic (GFRP) is characterized by high strength and rigidity coupled with low weight and, in many respects, is superior to metals. However, for the practical cutting of glass fiber, optimal cutting parameters should be taken into consideration to achieve less blade wear, good cutting quality, etc. In order to achieve this objective, how to control the blade wear correctly is decisive.

During glass fiber cutting, the reduction of blade wear is a critical aspect. Long glass fibers were found to affect cutting quality significantly. Lau et al. [2] showed that the wear characteristics of blades were highly influenced by the geometry and thickness of the blade. Casto et al. [3] discussed the lifetime according to different criteria, determined by using a profilometer and image processing, where the worn zone was observed using a scanning electron microscope (SEM). A Weibull distribution has been applied to a variety of cutting processes. Yang et al. [4] concluded that the effect of the cutting conditions, the cutting speed, the feed rate, and the depth of cut on the tool life and the cumulative probability of chipping could be presented as a Weibull distribution with three parameters. Lin [5] has observed that the cutting tool life can be represented for the cases studied by the statistical normal distribution. Moreover, Klim et al. [6] conducted a two-parameter study on the effect of feed variation on the tool wear and tool life, and found that this followed a Weibull distribution.

The Taguchi method [7] has produced a unique and powerful quality improvement discipline that differs from the traditional process. Since the product and process design have a great impact on the life cycle, the cost, and the quality of a component, the Taguchi design of experiment (DOE) approach provides a design engineer with a systematic method for determining the optimum design parameters to obtain the best performance at the lowest cost. Therefore, the Taguchi methods have become a widely acceptable methodology for improving productivity. However, the original Taguchi methods were designed to optimize a single performance characteristic. It is not the kind of condition that engineers deal 
with nowaday complex manufacturing process. Therefore, optimization of multiple performance characteristics is still interesting to researchers to do further study. Kang and Hadfield [8] designed a novel eccentric lapping machine, and in a systematic use of the Taguchi methods, they investigated the optimization of different lapping parameters. Lin [9] obtained optimal parameters using the Taguchi methods and analysis of the Weibull modulus through reliability engineering for the polishing of ceramic gauge blocks.

The Grey system theory proposed by Huang and Liao [10] has been proven to be useful for dealing with poor, incomplete, and unsure information. Chang et al. [11] presented a fast and effective methodology of Grey relational analysis for the optimization of the injection molding process parameters of short glass fiber reinforced polycarbonate composites. Lin and Lin [12] found the Grey relational analysis can be used to solve the electrical discharge machining (EDM) process with the multiple performance characteristics. The Grey relational analysis based on the Grey system theory by Deng [13] can be used to solve complicated inter-relationships among the multiple performance characteristics effectively.

To optimize several responses or quality characteristics simultaneously, many researchers have tried to combine the Taguchi methods with other methods $[14,15]$. Through the Grey relational analysis, a Grey relational grade is obtained to evaluate the multiple performance characteristics. As a result, optimization of the complicated multiple performance characteristics can be converted into optimization of a single Grey relational grade. Lin [14] has shown optimal cutting parameters can then be determined by the Taguchi methods using the Grey relational grade as the performance index. The cutting parameters, the tool life, the cutting force, and the surface roughness are important characteristics in turning. Lin et al. [15] used reliability analysis, the Taguchi and the Grey methods in this paper. The speed and the load are optimized polishing parameters when the performance characteristics, which include Weibull modulus and the removal rate, are taken into consideration.

In this paper, the reliability of the cutting process for glass fiber materials has been evaluated quantitatively in terms of a three-parameter Weibull distribution [4]. The effect of the cutting parameters, i.e. the cutting speed, the cutting volume, and the cutting load, on the blade wear, as determined by long glass fiber that would exceed a value of $1 \%$, to meet the requirement of the customer acceptance standard TP-700 of the Owens Corning Company, was investigated. When using the Taguchi methods of parameter design, the experimental details were used for optimizing the single performance charac- teristics. Optimization of multiple performance characteristics with the Grey relational analysis was also considered in this paper. The methodology used in the experiments was the same as that used by Lin [9], and was as the following:

1) Perform a Taguchi-based experiment.

2) Measure the material wear from 12 cuts by a cutter blade.

3) Calculate the Weibull modulus and the mean value of the wear.

4) Calculate the signal-to-noise $(S / N)$ ratio.

5) Collect the data while preprocessing both the mean value of the wear and the Weibull modulus.

6) Perform an analysis of variance (ANOVA) using the Grey relational analysis.

7) Carry out the confirmation runs.

\section{Reliability Analysis}

The reliability, determined from a three-parameter Weibull distribution, was expressed by Shigley et al. [16] as:

$$
R=\exp -\left(\left(x-x_{0}\right) /\left(s-x_{0}\right)\right)^{b} \quad x \geq x_{0}
$$

In it:

$x$ is the thin-edge blade wear $(\mu \mathrm{m})$;

$x_{0}$ is the guaranteed value of $y\left(x_{0} \geq 0\right)$;

$s$ is a characteristic or scale value $\left(s \geq x_{0}\right)$;

$b$ is the Weibull modulus $(b \geq 0)$.

The Weibull modulus is the most important parameter in a Weibull distribution. The increases of reliability depend on the increase of the Weibull modulus. The probability of a failure, $F=1-R$, can be calculated as indicated by Shaw [17] according to:

$$
F=(g-0.3) /(h+0.4)
$$

In which:

$g$ is the $g^{\text {th }}$ sample as the blade wear values are ranked in order;

$h$ is the total number of samples.

The detail for the relationship between the reliability and the wear rate has been derived by Yang et al. [4]. So, the guaranteed value $x_{0}$ can be written as

$$
x_{0}=x_{2}-\frac{\left(x_{3}-x_{2}\right)\left(x_{2}-x_{1}\right)}{\left(x_{3}-2 x_{2}+x_{1}\right)}
$$

The characteristic parameter $s$ can be written as

$$
s=i n v \ln \left(x-x_{0}\right)+x_{0}
$$

The Weibull modulus $b$ can be written as

$$
b=\Delta Y / \Delta x
$$

\section{Experiments}

The identified parameters that affect the characteristics of 
turned parts are the cutting blade parameters (blade geometry and blade material), the workpiece-related parameters (long fiber), the cutting parameters (speed, load, and volume), and the environmental parameters (dry cutting and wet cutting). The ranges of the selected cutting process parameters (cutting speed $\mathrm{V}=1.9-5.7 \mathrm{~m} / \mathrm{s}$, load $\mathrm{F}=13-27 \mathrm{kgf} / \mathrm{cm}^{2}$, and volume150 - 250 piece) are ascertained by conducting preliminary experiments. The details of the work material, the cutting machine, the cutting blade, and the cutting conditions are as the following:

The work material: E-glass fiber, $9 \mu \mathrm{m} \times 66(\mathrm{~g} / 1000$ $\mathrm{m})$.

The cutting machine: Parallel blade-cutting machine (Finn and Fram, USA) with a $0.75 \mathrm{HP}$ spindle power.

The cutting blade: Lutz cutter (Lutz, Germany) made of high-carbon steel disposable blades

The cutting condition: Dry

The wear measure: Examined by using a SEM to measure blade wear.

Glass fiber that were $9 \mu \mathrm{m}$ in diameter and 66 (g / $1000 \mathrm{~m}$ ) in weight and machined on a cutting machine with a carbon steel blade. The blade wear were measured by a SEM while each specimen was cut. The cutting blade samples were examined by a SEM to measure blade wear values at three points, and these were averaged to obtain an average blade wear value. Each cutting test of a blade wear was performed until the long glass fiber weight exceeded a value of $1 \%$, as specified in the customer acceptance standard TP-700 of the Owens Corning Company.

\section{The Single Performance Characteristic}

\subsection{The Taguchi Methods}

An orthogonal array gives a more reliable estimate of the factor effects with fewer tests compared to traditional methods. In this paper, based on the experiments designed by Kang and Hadfield [8], three levels of cutting parameters were selected and the three cutting parameters were used as control parameters, and each parameter was designed to have three levels, as shown in Table 1. Three major control factors (cutting speed, load, and volume) were selected to conduct the tests. All three factors are multilevel variables and their outcome effects have nonlinear relationships; hence, we used three-level tests for each factor. The number of degrees of freedom was calculated from the number of parameters identified and their number of levels of variation. Using the full factorial design $(3 \times 3 \times 3 \times 3)$ reduced a total of 81 sets of experiments down to 9 , thereby decreasing the cost, the time, and the effort. 9 the array along with the factors assigned to the columns was presented in Table 2, which consists of nine experiments corresponding to the nine rows and four columns. In this matrix, the chosen three parameters, the cutting speed, the cutting volume and the cutting load are assigned to the second, the third and the fifth columns. The fourth column was not assigned and used as an error term e. The nine experiments of the L9 array were carried out without the interaction effect.

\subsection{Analysis of $S / N$ ratio for the Smaller-the-Better Parameter}

The Taguchi methods use the $S / N$ ratio to analyze the average value of the test run data to derive values for evaluating the characteristic cutting parameters. This is because the $S / N$ ratio represents both the average and the variation in quality characteristics. The units of the $S / N$ ratio are decimals. The Taguchi parameter design is used to determine the optimum conditions of the engineering parameters (the controllable parameters), and also to minimize any variation in the noise (the uncontrollable parameters). The $S / N$ ratio provides a measure of the robustness. To find the optimal cutting conditions, the blade wear should be of lower order; hence, the $S / N$ for "the smaller the better" type of response is used:

$$
S / N_{S T B}=-10 \log \left[1 / n \sum y_{i}^{2}\right]
$$

Table 1. Cutting parameters and levels.

\begin{tabular}{cccccc}
\hline Symbol & Parameter & Unit & Level 1 & Level 2 & Level 3 \\
\hline A & Cutting speed & $\mathrm{m} / \mathrm{s}$ & 1.9 & 3.8 & 5.7 \\
B & Cutting volume & piece & 150 & 200 & 250 \\
C & Cutting load & Kgf $/ \mathrm{cm}^{2}$ & 27 & 20 & 13 \\
\hline
\end{tabular}

Table 2. The L9 $\left(3^{4}\right)$ orthogonal array used in Taguchi methods.

\begin{tabular}{ccccc}
\hline Group & A & B & e & C \\
\hline 1 & 1 & 1 & 1 & 1 \\
2 & 1 & 2 & 2 & 2 \\
3 & 1 & 3 & 3 & 3 \\
4 & 2 & 1 & 2 & 3 \\
5 & 2 & 2 & 3 & 1 \\
6 & 2 & 3 & 1 & 2 \\
7 & 3 & 1 & 3 & 2 \\
8 & 3 & 2 & 1 & 3 \\
9 & 3 & 3 & 2 & 1 \\
\hline
\end{tabular}


where $y_{i}$ is the mean value of the wear or Weibull modulus at the $i^{\text {th }}$ test and $n$ is the number of trials. $S / N_{S T B}$ is the smaller-the-better $S / N$ ratio.

To understand the blade wear during cutting, an experiment using S55C high-carbon steel blades to cut the glass fiber was carried out as shown in the schematic diagram in Figure 1. In a single experiment, 12 cutting blades were used to cut simultaneously. Table 3 shows the mean value of the wear and the corresponding $S / N$ ratio calculated by using Equation (6). Table 4 shows the Weibull modulus and the corresponding $S / N$ ratio calculated by using Equation (6).

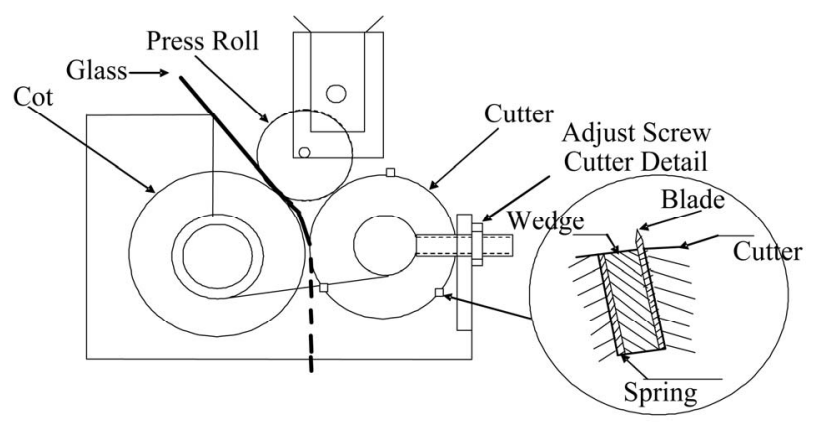

Figure 1. Schematic of cutting machine.

Table 3. Experimental results for the mean value of the wear and the $S / N$ ratio.

\begin{tabular}{ccc}
\hline Group & Mean value of wear $(\mu \mathrm{m})$ & $S / N$ ratio $(\mathrm{dB})$ \\
\hline 1 & 49.29 & -33.93 \\
2 & 40.03 & -32.24 \\
3 & 39.58 & -32.04 \\
4 & 63.05 & 36.05 \\
5 & 59.01 & -35.46 \\
6 & 55.21 & -34.93 \\
7 & 39.78 & -32.06 \\
8 & 64.39 & -36.22 \\
9 & 48.17 & -33.79 \\
\hline
\end{tabular}

Table 4. Experimental results for the Weibull modulus and the $S / N$ ratio.

\begin{tabular}{ccc}
\hline Group & Weibull modulus & $S / N$ ratio $(\mathrm{dB})$ \\
\hline 1 & 2.07 & -6.32 \\
2 & 8.65 & -18.74 \\
3 & 3.69 & -11.34 \\
4 & 6.75 & -16.59 \\
5 & 3.34 & -10.47 \\
6 & 6.04 & -15.62 \\
7 & 1.85 & -5.34 \\
8 & 4.27 & -12.61 \\
9 & 1.89 & -5.53 \\
\hline
\end{tabular}

\section{Multiple Performance Characteristics}

\subsection{Grey Relational Analysis}

In the Grey relational analysis, a data preprocessing is first performed in order to normalize the raw data, and a linear normalization of the experimental results for the mean value of the wear and the Weibull modulus is performed in the range between zero and one, which is also called the Grey relational generating $[13,18]$.

For the blade wear and weibull modulus, which are "the smaller the better", the normalized $S / N$ ratio $z_{i j}$ for the $i^{\text {th }}$ performance characteristic in the $j^{\text {th }}$ can be expressed as

$$
z_{i j}=\frac{\max y_{i j}-y_{i j}}{\max _{j} y_{i j}-\min _{j} y_{i j}}
$$

$y_{i j}$ for the $i^{\text {th }}$ experimental results in the $j^{\text {th }}$ experiment.

Next, the Grey relational coefficient is calculated to express the relationship between the ideal (best) and the actual normalized $S / N$ ratio. The Grey relational coefficient $\alpha_{i j}$ for the $\mathrm{i}^{\text {th }}$ performance characteristic in the $j^{\text {th }}$ experiment can be expressed as

$$
\alpha_{i j}=\frac{\min _{i} \min _{j}\left|z_{i}^{0}-z_{i j}\right|+\beta \max _{i} \max _{j}\left|z_{i}^{0}-z_{i j}\right|}{\left|z_{i}^{0}-z_{i j}\right|+\beta \max _{i} \max _{j}\left|z_{i}^{0}-z_{i j}\right|}
$$

where $z_{i}^{0}$ is the ideal normalized $S / N$ ratio for the $i^{\text {th }}$ performance characteristics and $\beta$ distinguishing coefficient which is setting as 0.5 in this article.

Then, the Grey relational grade is computed by averaging the Grey relational coefficient corresponding to each performance characteristic. The overall evaluation of the multiple performance characteristics is based on the Grey relational grade, that is

$$
\gamma_{j}=\frac{1}{k} \sum_{i=1}^{k} \alpha_{i j}
$$

In it:

$\gamma_{j}$ is the Grey relational grade for the $j^{\text {th }}$ experiment;

$k$ is the number of performance characteristics.

Table 5 shows the dada calculated by using Equation (7), the normalized results for the mean value of the blade wear and the Weibull modulus. Basically, the larger normalized results correspond to the better performance and the best normalized results should be equal to one. The grey relational coefficient results for the experimental layout are shown in Table 6.

Using the experimental combinations of Table 2, Table 7 shows the Grey relational grade for each experiment. The larger Grey relational grade indicates that the corresponding experimental result is closer to the ideally normalized value. Group 7 has the best multiple performance characteristics among the nine experiments 
because it has the highest Grey relational grade shown in Table 7. Since the experimental design is orthogonal, it is then possible to separate out the effect of each cutting parameter in different levels.

Figure 2 shows the Grey relational grade graph, where the dashed line in this figure is the value of the total mean of the Grey relational grade. Basically, the larger the Grey relational grade is, the better the multiple performance characteristics are. $\mathrm{A} 3 \mathrm{~B} 1 \mathrm{C} 2$ is the optimal level of cutting parameters with the multiple performance characteristics.

Table 5. Data preprocessing of experimental result for each performance characteristic.

\begin{tabular}{ccc}
\hline Group & Mean value of wear $(\mu \mathrm{m})$ & Weibull modulus \\
\hline 1 & 0.4504 & 0.0729 \\
2 & 0.0466 & 1.0000 \\
3 & 0.0000 & 0.4476 \\
4 & 0.9583 & 0.8392 \\
5 & 0.8192 & 0.3830 \\
6 & 0.6921 & 0.7671 \\
7 & 0.0032 & 0.0000 \\
8 & 1.0000 & 0.5423 \\
9 & 0.4183 & 0.0139 \\
\hline
\end{tabular}

Table 6. Grey relational coefficient of each performance characteristic.

\begin{tabular}{ccc}
\hline Group & Mean value of wear $(\mu \mathrm{m})$ & Weibull modulus \\
\hline 1 & 0.5261 & 0.8728 \\
2 & 0.9147 & 0.3333 \\
3 & 1.0000 & 0.5276 \\
4 & 0.3429 & 0.3734 \\
5 & 0.3790 & 0.5662 \\
6 & 0.4194 & 0.3946 \\
7 & 0.9936 & 1.0000 \\
8 & 0.3333 & 0.4797 \\
9 & 0.5445 & 0.9730 \\
\hline
\end{tabular}

Table 7. Grey relational grade for each experiment.

\begin{tabular}{ccc}
\hline Group & Grey relational grade & Order \\
\hline 1 & 0.6994 & 4 \\
2 & 0.6240 & 5 \\
3 & 0.7638 & 2 \\
4 & 0.3581 & 9 \\
5 & 0.4726 & 6 \\
6 & 0.4070 & 7 \\
7 & 0.9968 & 1 \\
8 & 0.4065 & 8 \\
9 & 0.7588 & 3 \\
\hline
\end{tabular}

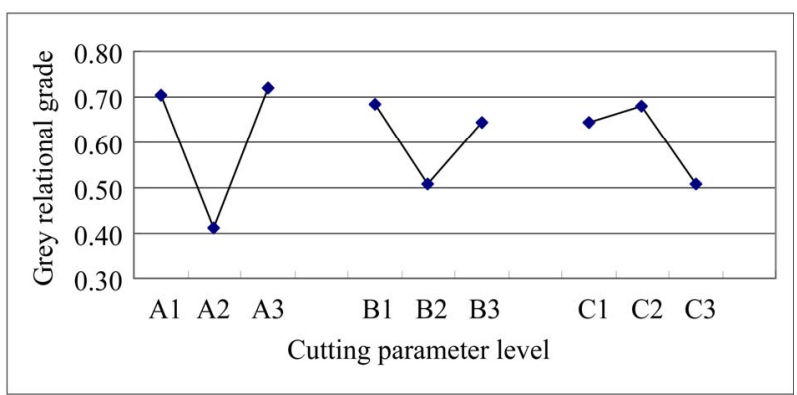

Figure 2. Grey relational grade graph.

\subsection{Analysis of Variance}

The ANOVA scheme was used to study the significance of the parameters affecting the quality characteristics of the interest. The scheme subdivides the total variation in the data into useful and meaningful components of variation. The total variation contribution is shown in Table 8. The ANOVA results in Table 8 clearly identify that the cutting speed and the volume severely affected the blade wear by $47.21 \%$ and $14.62 \%$, respectively, while the load only affected the blade wear by $12.20 \%$.

\subsection{Confirmation Tests}

A confirmation experiment is the final step in the design of experiment process. Once the optimum level of the design parameters is set, the final step can predict and verify the quality characteristic using the optimum level $\eta_{\text {opt }}$ of the design parameters, which can also be estimated by using the equation

$$
\eta_{\text {opt }}=\bar{\eta}+\sum_{j=1}^{0}\left(\eta_{i}-\bar{\eta}\right)
$$

In which:

$\bar{\eta}$ is the mean of the $S / N$ ratio;

$\eta_{j}$ is the $S / N$ ratio at the optimum level;

$o$ is the number of main design parameters that affects the optimum level of the cutting parameters.

From Equation (10), the estimated optimum design parameters can be obtained by using the optimum cutting parameters.

A pareto chart generated based on the contribution ratio is presented in Figure 3. This chart shows the importance of the significant parameters. Table 9 shows a comparison among the initial, predicted, and confirmation experimental values of the wear, respectively, using the optimum cutting parameters. Table 9 shows the results of the confirmation experiment for the mean value of the wear. The results of the confirmation experiment of the predicted optimal conditions A3B1C2, which was better than the initial trial. As shown in Table 9, the blade wear decreases from 64.73 to 39.43 , when the 
Table 8. Results of analysis of variance for multiple performance characteristic.

\begin{tabular}{ccccc}
\hline Symbol & Cutting parameter & Sum of square & Degree of freedom & Contribution (\%) \\
\hline A & Cutting speed & 0.18 & 2 & 47.21 \\
B & Cutting volume & 0.06 & 2 & 14.62 \\
C & Cutting load & 0.05 & 2 & 12.20 \\
Error & & 0.09 & 2 & 25.97 \\
Total & & 0.37 & 8 & 100.00 \\
\hline
\end{tabular}

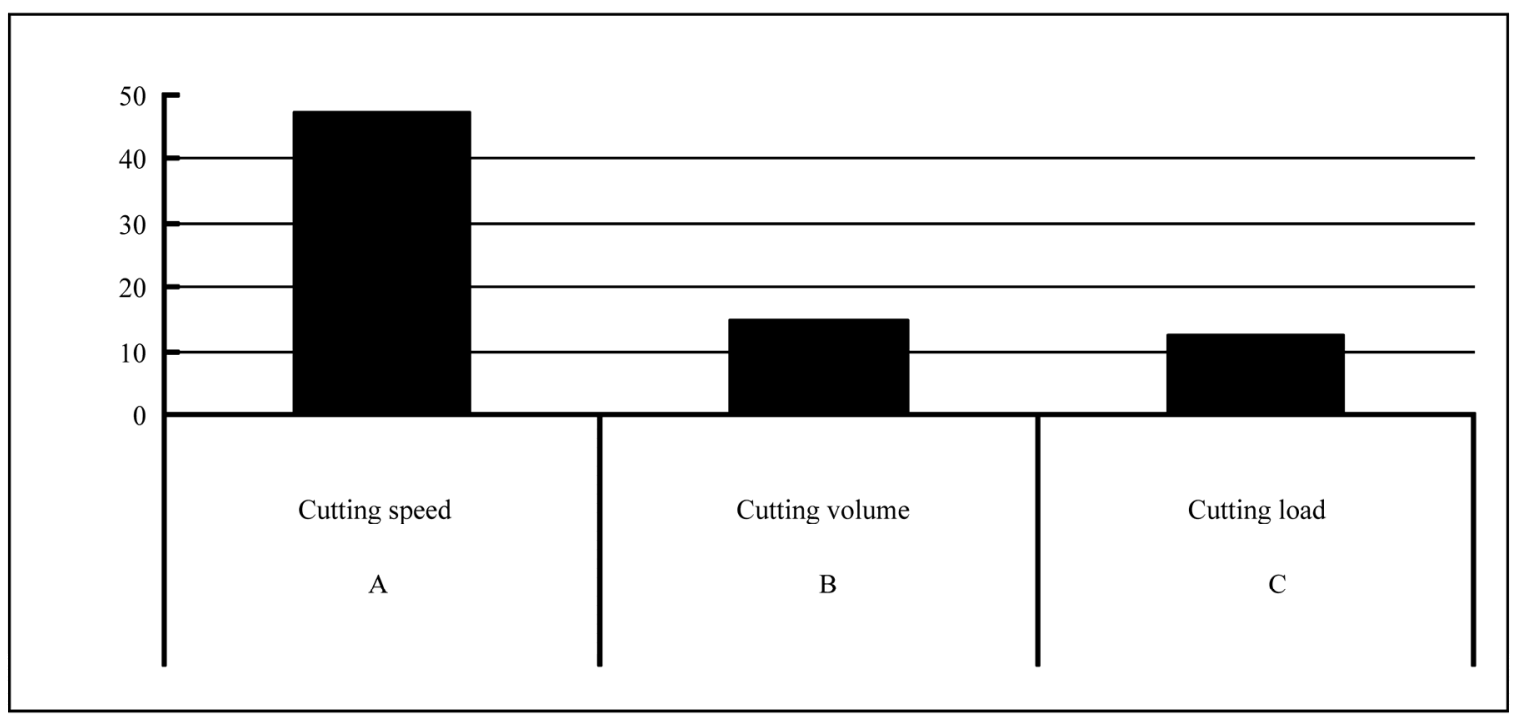

Figure 3. Pareto chart.

Table 9. Results of the confirmation experiment.

\begin{tabular}{lccc}
\hline \multicolumn{1}{c}{ Cutting parameter } & Initial & Predicted & Confirmation experiment \\
\hline Level & A2B2C2 & A3B1C2 & A3B1C2 \\
Wear $(\mu \mathrm{m})$ & 64.73 & - & 39.43 \\
Weibull modulus & 1.90 & - & 1.85 \\
Grey relational grade & 0.4498 & 0.9332 & 0.9968 \\
Improvement of grey relational grade & - & - & 0.5470 \\
Improvement in wear $(\%)$ & - & - & 64.16 \\
\hline
\end{tabular}

Weibull modulus is decreased from 1.9 to 1.85 . In summary, the most optimal cutting parameter should be $\mathrm{A} 3 \mathrm{~B} 1 \mathrm{C} 2$, because the improvement is the greatest by using this parameter, and it is obvious that the optimum level of the cutting parameters in the cutting process is greatly improved.

Conducting a verification experiment is a crucial and the last step of the robust design procedure. Its aim is to verify the optimum conditions identified by the matrix tests and it estimates how close the predictions are to actual conditions. Hence, a confirmation test was conducted with the optimum parameters, and came out in good result.

\section{Conclusions}

This paper has carried out the optimization in the cutting of glass fiber. The following conclusions are obtained from analyzing the above stated experimental results: 
1) The multiple parameters for multiple performance characteristics are found to be the higest speed, the smaller cutting volume and the medium load.

2) To study further within the experimental range used, we found that the most significant cutting parameter for multiple performance characteristics are the cutting speed, which accounts for $47.21 \%$ of the total effect, followed by the cutting volume (14.62\%), and the cutting load, which accounts for only $12.20 \%$ of the total effect.

3) In summary, the most optimal cutting parameter is A3B1C2.

4) In the cutting glass fiber, using reliability analysis with Grey-based Taguchi methods is a good way to improve the multiple performance characteristics.

\section{REFERENCES}

[1] S. O. An, E. S. Lee and S. L. Noh, "A Study on the Cutting Characteristics of Glass Fiber Reinforced Plastics with Respect to Tool Materials and Geometries," Journal of Materials Processing Technology, Vol. 68, No. 1, 1997, pp. 60-67. doi:10.1016/S0924-0136(96)02534-4

[2] K. H. Lau, D. Mei, C. F. Yeung and H. C. Man, "Wear Characteristics and Mechanisms of a Thin Edge Cutting Blade, "Journal of Materials Processing Technology, Vol. 102, No. 1-3, 2000, pp. 203-207. doi:10.1016/S0924-0136(99)00410-0

[3] S. L. Casto, E. L. Valvo, E. Lucchini, S. Maschio and V. F. Ruisi, "Wear Rates and Wear Mechanisms of Alumina-Based Tools Cutting Steel at a Low Cutting Speed," Wear, Vol. 208, No. 1-2, 1997, pp. 67-72. doi:10.1016/S0043-1648(96)07376-0

[4] C. L. Yang, S. H. Sheu and K.T. Yu, "The Reliability Analysis of a Thin-Edge Blade Wear in the Glass Fiber Cutting Process," Journal of Materials Processing Technology, Vol. 209, No. 4, 2009, pp. 1789-1795. doi:10.1016/j.jmatprotec.2008.04.028

[5] W. S. Lin, "The Reliability Analysis of Cutting Tools in the HSM Processes," Archives of Materials Science and Engineering, Vol. 30, No. 2, 2008, pp. 97-100.

[6] Z. Klim, E. Ennajimi, M. Balazinski and C. Fortin, "Cutting Tool Reliability Analysis for Variable Feed Milling of 17-4PH Stainless Steel," Wear, Vol. 195, No. 1-2, 1996, pp. 206-213. doi:10.1016/0043-1648(95)06863-5

[7] P. J. Ross, "Taguchi Techniques for Quality Engineering," McGraw-Hill Book Company Press, New York, 1996.
[8] J. Kang and M. Hadfield, "Parameter Optimization by Taguchi Methods for Finishing Advanced Ceramic Balls Using a Novel Eccentric Lapping Machine," Proceedings of the Institution of Mechanical Engineers, Part B: Journal of Engineering Manufacture, Vol. 215, No. 1, 2001, pp. 69-78. doi:10.1243/0954405011515145

[9] T. R. Lin, "The Use of Reliability in the Taguchi Method for the Optimization of the Polishing Ceramic Gauge Block," The International Journal of Advanced Manufacturing Technology, Vol. 22, No. 3-4, 2003, pp. 237-242. doi:10.1007/s00170-002-1465-1

[10] J. T. Huang and Y. S. Liao, "Optimization of Machining Parameters of Wire-EDM Based on Grey Relational and Statistical Analyses," International Journal of Production Research, Vol. 41, No. 8, 2003, pp. 1707-1720. doi:10.1080/1352816031000074973

[11] S. H. Chang, J. R. Hwang and J. L. Doong, "Optimization of the Injection Molding Process of Short Glass Fiber Reinforced Polycarbonate Composites Using Grey Relational Analysis," Journal of Materials Processing Technology, Vol. 97, No. 1-3, 2000, pp. 186-193. doi:10.1016/S0924-0136(99)00375-1

[12] J. L. Lin and C. L. Lin, "The Use of the Orthogonal Array with Grey Relational Analysis to Optimize the Electrical Discharge Machining Process with Multiple Performance Characteristics," International Journal of Machine Tools and Manufacture, Vol. 42, No. 2, 2002, pp. 237-244. doi:10.1016/S0890-6955(01)00107-9

[13] J. L. Deng, "Introduction to Grey System Theory," Journal of Grey System, Vol. 1, No. 1, 1989, pp.1-24.

[14] C. L. Lin, "Use of the Taguchi Method and Grey Relational Analysis to Optimize Turning Operations with Multiple Performance Characteristics," Materials and Manufacturing Processes, Vol. 19, No. 2, 2004, pp. 209220. doi:10.1081/AMP-120029852

[15] T. R. Lin, H. C. Chiu and M. F. Huang, "Optimizing Removal Rate and Reliability of Polishing of Ceramic Blocks Using a Combination of Taguchi and Grey Method," Institute of Materials Minerals an Mining, August 2004.

[16] J. E. Shigley, C. R. Mischke and R. G. Budynas, "Mechanical Engineering Design," 7th Edition, McGraw-Hill Press, New York, 2003.

[17] M. C. Shaw, "Metal Cutting Principles," Oxford Science Press, New York, 2004.

[18] K. L. Wen, Y. W. Huang, W. C. Chung, T. C. Chung, M. L. You and C. J. Lai, "Method and Application of Grey Model," Gau-Lih Press, Taipei, 2003. 